\title{
Development of Numerical Method Multimedia Content in Online Learning Environment to Improve Student Learning Outcomes
}

\author{
Syafii $^{1 *}$, Heru Dibyo Laksono ${ }^{1}$ \\ ${ }^{I}$ Department of Electrical Engineering, Engineering Faculty, Universitas Andalas, Padang, Indonesia \\ *Corresponding author. Email: syafii@eng.unand.ac.id
}

\begin{abstract}
Multimedia content based on online learning is needed for education in a pandemic era and new normal period. This article describes the development of numerical method multimedia content in online learning environment to improve student learning outcomes. The results of the Numerical Method Course development consists of semester learning plans (SLP) based on blended learning and the interactive learning (iLearn) contents improvement. For the implementation of blended learning SLP in the odd semester of the academic year 2020/2021, especially for the first half semester learning (learning before the odd mid-semester), four online learning videos have been made which can be accessed by students via the YouTube link from iLearn of Universitas Andalas. The pdf materials and videos used as asynchronized learning and the WhatsApp chat and Zoom meeting have been used as synchronized discussion learning. Therefore, the application of technology becomes an instrument in realizing good and quality education to provide convenience, efficiency and effectiveness to improve student learning outcomes.
\end{abstract}

Keywords: Numerical method course, student learning outcome, pandemic era and multimedia content

\section{INTRODUCTION}

The numerical method is one of the groups of basic skills taught at the Department of Electrical Engineering, Faculty of Engineering, Andalas University. The numerical method is a technique used to formulate mathematical problems so that they can be solved by calculation operations and ordinary arithmetic using the add, subtract, multiply, and divide operations [1]. Method means method, while numeric means numbers. So the numerical method literally means how to count using numbers. The numerical method has always been associated with the development of computers, because the development of the numerical method itself originated from the invention of the computer. With computer programs complex math problems can be solved numerically easily.

The important problem in numerical method is finding the right algorithm to solve the problem and interpreting the algorithm into a computer programming language. In numerical method learning is usually done by modeling the system into mathematical equations, obtaining a solving algorithm and creating a Visual C ++ based computer program. With numerical analysis complex engineering problems can be solved easily using computers.
Based on the results of an internal quality audit conducted by LP3M, Andalas University, it shows that the use of e- learning in lectures at Andalas University is still lacking. Previously, Numerical Method lectures in the Electrical Engineering Department were still given face-to-face conventionally. Introducing courses in the form of semester learning plans (SLP) which are uploaded on the e-learning web. The previous studies show that the blended learning [2] and E-learning model on student performance are very effective [3]. The blended learning can be synchronous and asynchronous mode in online learning environment [4]. Therefore, through the Blended Learning Development and Implementation Research Grant (PPBL) program for the 2020 Fiscal Year, it is hoped that it can increase the use of digital/online technology in Numerical Methods learning at Andalas University. The blended learning with various online contents supports the Industrial Revolution 4.0 and becomes a learning solution during the Covid 19 pandemic. During the pandemic, remote learning became a lifeline for education [5].

The objectives of this proposed program are:

1. Providing knowledge and skills of numerical methods so that students are able to solve complex problems in engineering using computers. 
2. Give lectures by combining the use of elearning and conventional face-to-face learning.

The Outcome-Based Education (OBE) method have been adopted in numerical method course learning. $\mathrm{OBE}$ is an approach that emphasizes the sustainability of the learning process in an innovative, interactive and effective manner. OBE affects the entire educational process of the curriculum design; formulation of learning objectives and outcomes; educational strategy; learning method design; assessment procedures; and environment / education ecosystem. The target of the Numerical Method course is for all students of the Department of Electrical Engineering, Andalas University in particular and in other departments at the Faculty of Engineering. The scope of the Numerical Method course will be taught in the form of blended learning.

\section{SUBJECT DESCRIPTION}

The Numerical Method course is a basic skill course in the odd semester of the third year that must be taken for Bachelor Electrical Engineering Study Program students. The numerical method is used to formulate mathematical problems so that they can be solved by calculation operations and ordinary arithmetic using the add, subtract, multiply, and divide operations using a computer. With computer programs complex math problems can be solved numerically easily. Topic in lectures.

The formulation of learning outcomes begins with the student learning outcome (SLO) at the Study Program level as shown in Table 1. The subject learning outcomes is downgraded from student learning outcome. The curriculum is structured by first determining learning outcomes, then the model and assessment system, and then the learning process is designed.

Table 1. Learning Outcomes

\begin{tabular}{l|l}
\multicolumn{1}{c|}{ Code } & \multicolumn{1}{|c}{ Program 's learning outcomes } \\
\hline S10 & $\begin{array}{l}\text { Demonstrate an attitude of responsibility } \\
\text { for work in their field of expertise } \\
\text { independently }\end{array}$ \\
\hline P1 & $\begin{array}{l}\text { Ability to apply knowledge of } \\
\text { mathematics, natural and / or material } \\
\text { science, information technology and } \\
\text { engineering to gain a comprehensive } \\
\text { understanding of engineering principles. }\end{array}$ \\
\hline KU5 & $\begin{array}{l}\text { Able to make decisions appropriately in } \\
\text { the context of problem solving in their } \\
\text { area of expertise, based on the results } \\
\text { of information and data analysis. }\end{array}$ \\
\hline
\end{tabular}

\begin{tabular}{l|l}
\hline KK10 & $\begin{array}{l}\text { Able to apply mathematics, science, and } \\
\text { engineering principles to solve complex } \\
\text { engineering problems in electric power } \\
\text { systems, telecommunications systems } \\
\text { and control systems. }\end{array}$ \\
\hline
\end{tabular}

The lecture material for the Numerical Method is described in eight chapters as follows:

Chapter 1. Algorithms and Programming

Chapter 2. Roots of Non-Linear Equations

Chapter 3. Interpolation

Chapter 4. Numerical Integral

Chapter 5. Numerical Differential Equations

Chapter 6. Matrics and Matrix Operations

Chapter 7. Systems of Linear Equations

Chapter 8. The object-oriented Nomeric Method

Each material will be equipped with examples of questions and solutions, algorithms and program code using $\mathrm{C}++$ visual programming. At the end of the material, practice questions will be given to test the reader's understanding of the material presented for the chapter in question using online learning facilities using Moodle-based iLearn, zoom meeting and skype.

\section{METHODOLOGY AND STRATEGY FOR ACHIEVING OUTPUTS}

The Numerical Method course is a basic skill course taught in the Electrical Engineering Department in the fifth semester. Students who will take the Numerical Method lectures in the Department of Electrical Engineering, Andalas University are all students of the 2018 class and added to previous year's students who did not graduate or repeat. Therefore, the projection of students who will take Numeric Method lectures based on blended learning in the odd semester of the academic year 2020/2021 around 160 electrical engineering students of Andalas University.

Through the process of implementing the Numeric Method course based on blended learning, it is expected that students have the ability to explain the basics of algorithms and programming, be able to solve problems of nonlinear equation roots, interpolation, integrals, differential equations and numerical systems of linear equations. In addition, students must have soft skill competencies which consist of intrapersonal skills such as independence, critical thinking, analytical and interpersonal skills such as teamwork skills, ability to use IT technology, being able to communicate well, and character basic values such as integrity, discipline, hard work, polite, ethical and confident. 
Planning and development of learning methods and student assessments of the Numerical Method Subject is carried out in several stages of activities as follows:

1. Learning plan

Improved the semester learning plan for the Numerical Method Subject based on the SCL approach with a blended learning system. The learning process for the Numerical Method course will be carried out based on the SLP using the Unand iLearn platform using Skype media for faceto-face lectures and discussions.

2. Development of learning methods

The learning method uses a combination of TCL and SCL by combining the use of e-learning and video conferencing using Skype. The TCL technique is still used around the first 30 minutes of the lecture, the rest is followed by the SCL technique with learning and Skype facilities. The SCL technique will use a small group discussion pattern and provide case studies. The ability to work in teams, use of technology, oral communication, logical argument, critical thinking and analytical thinking will increase with the group discussion. In each material given examples of questions and solutions, students must be able to compile algorithms and visual $\mathrm{C}$ program code, as well as run computer programs and collect them through the learning site.

3. Development of student assessments

At the end of each chapter, an exercise question is given to test students' understanding of the material presented for the chapter in question. In addition, there is a soft skill assessment through a group presentation assessment document. This assessment document will be prepared to assess team work skills, use of IT technology, oral communication, logical argument, critical thinking and analytical thinking in the learning system.

4. Classroom Action Research Parameters (CAR)

The general output expected from CAR related to affective, cognitive and psychomotor elements are as follows:

- Improvement or improvement of student learning performance and the quality of the learning process in the classroom.

- Can formulate mathematical models and derive appropriate algorithms in numerical solving problems in Electrical Engineering.

- Can translate algorithms into computer programsusing Visual C programming.

- Have soft skill competences, both intrapersonal skills and interpersonal skills.
- Improvements to the quality of curriculum implementation and competency development of Electrical Engineering Study Program students.

At the end of each chapter, a formative assessment is carried out by giving practice questions to test students' understanding of the material presented for the relevant chapter. In the middle there will be a midterm exam and at the end there will be a final semester exam to assess the summative achievement of student competencies in numerical method courses. The assessment documentation is stored in the learning database so that students can know the progress of their lectures from time to time and the lecturer can easily recap the results of student assessments.

The e-learning development includes plans for making learning videos for a minimum of 4 videos for 4 meetings. The video will be made using Skype by preparing the presentation material and recording it. The results of the Numerical Method learning video recordings will then be edited and animated using the Filmora 9 software, making it more interesting. The learning content developed is the course material before the mid test, namely:

Chapter1.The Roots of Non-Linear Equations (Quotation Method and False Position)

Chapter 2.The Roots of Non-Linear Equations (Newton Raphson and Secant Method)

Chapter 3. Interpolation Chapter 4. Numerical Integral

Learning assessment is done through giving quizzes at several meetings and mid term test.

\section{RESULT AND DICUSSION}

\subsection{Previous assessment of the course}

The results of the assessment of course learning outcomes can be seen in Figure 1 and Table 2 .

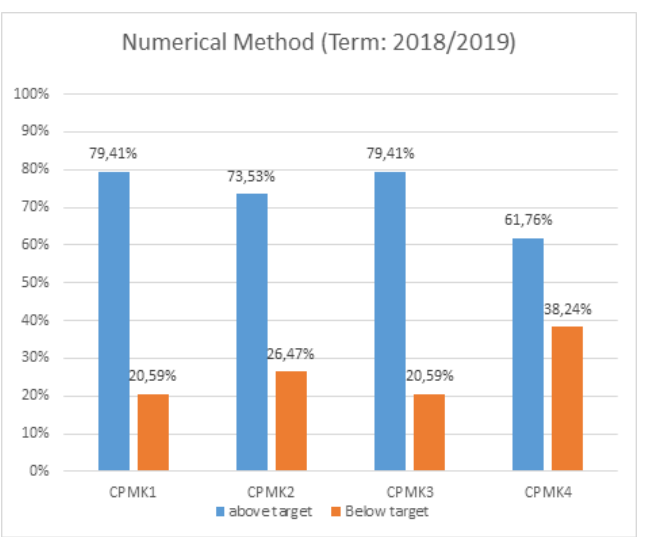

Figure 1. Learning outcome achievement

Students have been able to achieve all the Course learning outcome (CLO) targets. For CLO 4 there are 
still $38.24 \%$ of students who get score $<60 \%$, so that the ability of students to complete the linear equation system numerically using direct and iterative methods needs to be improved.

Tabel 2. Course learning outcome evaluation

\begin{tabular}{l|l|l|l} 
No & $\begin{array}{l}\text { Student } \\
\text { Outcomes }\end{array}$ & Realization & $\begin{array}{l}\text { Evaluati } \\
\text { on }\end{array}$ \\
\hline 1. & CLO 1 & $\begin{array}{l}79,41 \% \text { students get } \\
\text { grades } \geq 75 / 100\end{array}$ & achieved \\
\hline 2. & CLO 2 & $\begin{array}{l}73,53 \% \text { students get } \\
\text { grades }>60 / 100\end{array}$ & achieved \\
\hline 3. & CLO 3 & $\begin{array}{l}79,41 \% \text { students get } \\
\text { grades } \geq 60 / 100\end{array}$ & achieved \\
\hline 4. & CLO 4 & $\begin{array}{l}61,76 \% \text { students get } \\
\text { grades } \geq 60 / 100\end{array}$ & achieved \\
\hline
\end{tabular}

\subsection{Multimedia Content Development}

The learning video for the numerical method course was made using Zoom meeting recordings, then combined with the opening, mp4 files using the Filmora9 software. The explanation of the numerical calculation process was made using the help of the Wacom Intious CTL- 4100 pen tablet. The results of the development of the Numerical Method Course consisted of four online learning videos that could be accessed by students via a youtube link placed in the Unand iLearn, the design of the Ilerning Web page and the SLP blended learning as follows:

\section{Link Video}

Link video 1:

https://www.youtube.com/watch?v=MjL_KkEEYoo\&t= $\underline{1035 \mathrm{~s}}$

Link video 2:

https://www.youtube.com/watch?v=7_YnrOAtz0w\&t= $\underline{490 \mathrm{~s}}$

Link video 3:

https://www.youtube.com/watch?v=UijzZaKCsUk

Link video 4 :

https://www.youtube.com/watch? $\mathrm{v}=\mathrm{XjsMkkyaaFk \& t=}$ $\underline{807 \mathrm{~s}}$

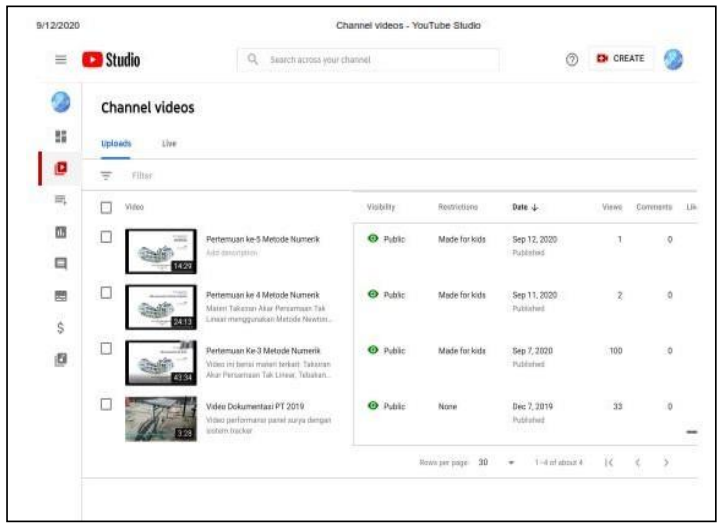

Figure 2. YouTube studio channel

Furthermore, the recorded video is uploaded via the YouTube studio channel under the KBK System account as shown in Figure 2. The results of the video upload in the KBK Sistem account are shown in Figure 3 which consists of 4 learning videos.

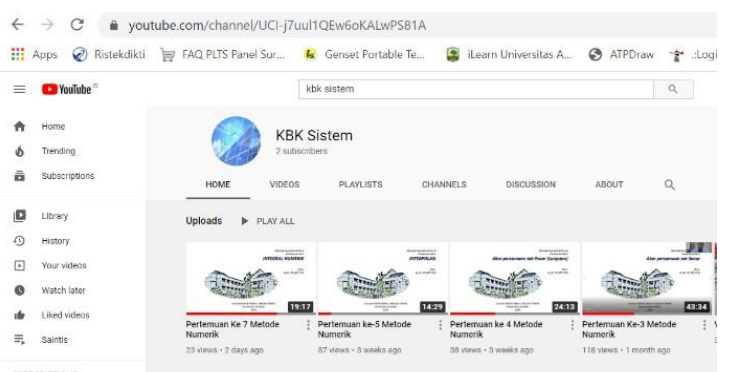

Figure 3. List of videos in KBK Sistem Youtube account

In order to optimize the use of information technology to support learning activities, Universitas Andalas have built iLearn systems. The iLearning implemented with an integrated on-line learning paradigm using Moodle Learning Management System (LMS). The layout of Numerical Methods iLearn Website as shown in Figure 4.

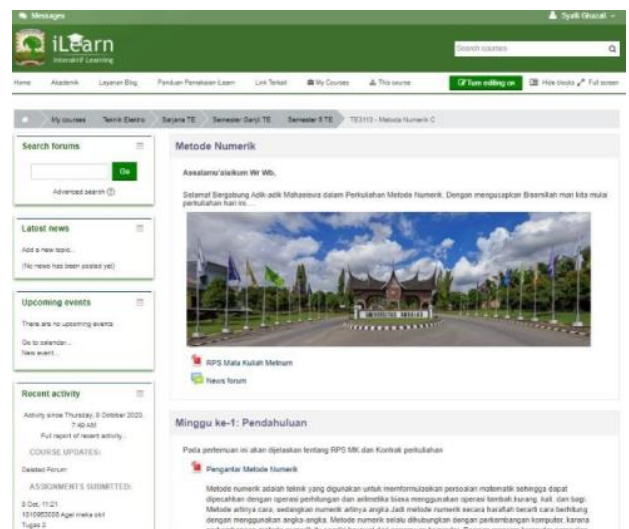

Figure 4. Layout of Numerical Methods iLearn Web

The iLearn view at the $3 \mathrm{rd}, 4$ th, 5 th and 7 th class after adding the video is shown in Figures 5 and 6. There are the video image and can be clicked by student to access the material. 


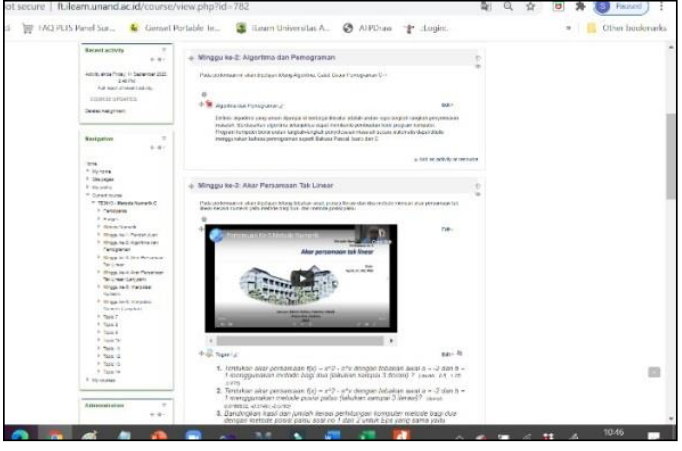

Figure 5. YouTube video in iLearn

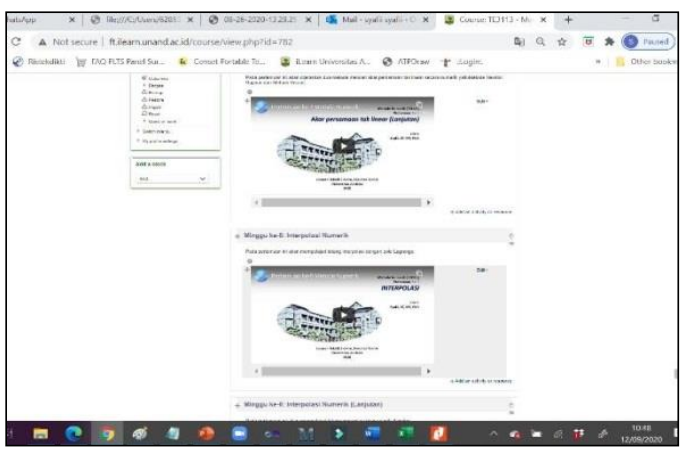

Figure 6. Two videos in in iLearn

The assessment process consists of an assessment of the test results and an assessment of the learning process as shown in table 3. The form of assessment Subjects can take advantage of the features available on the iLearn page.

Tabel 3. Components and presentation of the Numerical Method assessment

\begin{tabular}{|c|c|c|}
\hline No & Assessment Components & $\begin{array}{c}\text { Weig } \\
\mathrm{h}\end{array}$ \\
\hline \multicolumn{3}{|c|}{ Assessment from examination } \\
\hline 1. & Midterm exam & 25 \\
\hline 2. & Final exam & 25 \\
\hline \multicolumn{3}{|c|}{ Assessment of process } \\
\hline 1. & $\begin{array}{l}\text { Independence, critical and analytical } \\
\text { thinking, responsibility (Independent } \\
\text { Task) }\end{array}$ & 20 \\
\hline 2. & $\begin{array}{l}\text { Integrity, discipline, hard work, courtesy / } \\
\text { ethics / values, and confidence (character) } \\
\text { and teamwork, oral and written } \\
\text { communication (soft skills) } \\
\text { (Group task) }\end{array}$ & 20 \\
\hline 3 & Presence & 10 \\
\hline
\end{tabular}

Total

Assessment of the process consists of independent assignments, group assignments and attendance. Each student will conduct four group discussions and presentations as well as four self-administered assignments with competencies and assessments such as Table 3. Assessment of student understanding of the material provided is carried out through midterm exam and final exam. Midterm exam assessment is taken from course material up to mid-semester, while final exam assessment is taken from material after the middle of the semester until the end of the semester. So the two types of exams are separate with each assessment percentage of $25 \%$.

\section{CONCLUSION}

The development of multimedia content using numerical methods in an online learning environment to improve student learning outcomes has been carried out. The result of the development of the Numeric Method course is in the form of blended learning SLP. For the implementation of blended learning SLP odd semester of academic year 2020/2021, specifically for the first semester learning (learning before the odd semester), four online learning videos have been made which can be accessed by students via a youtube link placed in iLearn Unand. The results of the evaluation of the implementation of the blended learning SLP will be seen from the results of the online midterm exam and the portfolio of assignments, attendance and activeness in learning during online lectures. Technology becomes an instrument in realizing good and quality education that provides convenience, efficiency and effectiveness in a learning process.

\section{ACKNOWLEDGMENT}

The author would like to thank LP3M Unand for their assistance and financial support through the PPBL 2020 Grant No Contract. T. 32 /UN.16.18/PT.01.03/2020

\section{REFERENCES}

[1] S. Aminah, "Development of blended learning model in numerical method course," Int. J. Teach. Learn. Math., vol. 1, no. 2, p. 66, 2018.

[2] Y. Zhonggen, "Blended learning over two decades," Int. J. Inf. Commun. Technol. Educ., vol. 11, no. 3, pp. 1-19, 2015.

[3] A. I. Gambari, A. T. Shittu, O. O. Ogunlade, and O. R. Osunlade, "Effectiveness of blended learning and eLearning modes of instruction on the performance of undergraduates in 
Kwara State, Nigeria," Malaysian Online J.

Educ. Sci., vol. 5, no. 1, pp. 25-36, 2017.

[4] F. Martin, D. Polly, and A. Ritzhaupt, "Bichronous Online Learning: Blending Asynchronous and Synchronous Online Learning," Educ. Rev., no. September, pp. 1-11, 2020.

[5] A. Schleicher, "The impact of COVID-19 on education - Insights from Education at a Glance 2020." [Online]. Available:

http://www.oecd.org/education/education-at-aglance-19991487.htm. 